\title{
Nuclear magnetic resonance spectroscopy of excised human hearts
}

F Brunotte, B Peiffert, J M Escanye, G Pinelli, J Zamorano, P M Walker, J Robert, J P Villemot
Laboratoire de Biophysique, Nancy, France

F Brunotte

J M Escanye

P M Walker

J Robert

Chirurgie cardiaque Hôpital de Brabois

Rue de Morvan,

Vandoeuvre, France

B Peiffert

G Pinelli

J Zamorano

J P Villemot

Correspondence to:

Dr F Brunotte,

Laboratoire de Biophysique, Faculté de médecine,

21033 Dijon cedex, France.

Accepted for publication

18 November 1991

\begin{abstract}
Background-Phosphorus nuclear magnetic resonance spectroscopy has been proposed as a method of studying the metabolism of the myocardium in patients. Little is known about ${ }^{31} P$ nuclear magnetic resonance spectroscopy of diseased human hearts.

Methods-Two donor hearts meeting the requirements for heart transplantation and 11 diseased hearts were removed during a transplantation procedure and were studied in a horizontal $2.35 T$ superconducting magnet. Spectra were obtained at $0^{\circ} \mathrm{C}$ about 30 minutes after the excision. The areas of the inorganic phosphate peak (Pi) and of the phosphocreatine peak (PCr) were summed and expressed as a ratio with respect to the area of the $\beta$ ATP peak.
\end{abstract}

Results-The ratio (Pi + PCr)/ $\beta$ ATP was found to be significantly lower in five hearts with a myocardial infarct $(0.77$ $(0 \cdot 18))$ than in hearts with dilated cardiomyopathy $(1.25(0.29))$ and in normal hearts $(1.69(0.11))$. The area of the phosphodiester peak was expressed as a ratio with respect to the area of the $\beta$ ATP peak: no differences were found between the three groups.

Conclusions-These results suggest that the phosphocreatine concentration is lower in ischaemic heart disease than in dilated cardiomyopathy and that the phosphodiester peak is probably not useful in distinguishing between these two types of heart disease.

\section{(Br Heart J 1992;68:272-5)}

Our knowledge of the energetics of failing human myocardium is limited. Magnetic resonance spectroscopy proved useful for studying the metabolism of isolated perfused hearts. ${ }^{1}$ In recently published studies, localised phosphorus nuclear magnetic resonance spectroscopy has been used to measure myocardial high energy phosphates and phosphorylated lipids in vivo. ${ }^{2-4}$ Results obtained by this method should be interpreted cautiously since a contamination of spectra by contributions from the blood or from the chest wall muscles is commonplace. Using magnetic resonance spectroscopy we have assessed donor and recipient hearts in a programme of heart transplantation. In such in vitro conditions the whole heart can be studied without contributions from the chest wall or blood.

\section{Patients and methods}

PATIENTS

In eleven patients undergoing a heart transplantation the heart was arrested by a cardioplegic medium and excised. All recipients were in class IV of the New York Heart Association at the time of the transplantation: one patient had valve disease, five had dilated cardiomyopathy with a mean (SD) systolic pulmonary artery pressure 47 (10) $\mathrm{mm} \mathrm{Hg}$ and an ejection fraction $22.4(6.9) \%$, five patients had three vessel coronary artery disease at coronary arteriography with a previous myocardial infarct with a mean systolic pulmonary artery pressure $53.9(14 \cdot 2)$ $\mathrm{mm} \mathrm{Hg}$ (non-significant) and an ejection fraction of $24.8(8 \cdot 1) \%$. We also studied the hearts of two patients meeting the criteria of heart donor.

EXCISION OF THE HEARTS

The donor and recipient hearts were examined in the same manner. The cardioplegic medium had the following composition: $\mathrm{Na}^{+} 147 \mathrm{mmol} / 1, \mathrm{~K}^{+} 20 \mathrm{mmol} / \mathrm{l}, \mathrm{Ca}^{++}$ $2 \mathrm{mmol} / \mathrm{l}, \mathrm{Mg}^{++} 16 \mathrm{mmol} / 1, \mathrm{Cl}^{-} 203 \mathrm{mmol} / 1$. Cardioplegic arrest was obtained by infusing 2 litres of this solution into the aortic root. The hearts were removed and placed in two sterile plastic bags and in a plastic container filled with ice. All the hearts were studied between 15 and 30 minutes after excision. Depending on the availability of the magnet some of the hearts were studied several times.

\section{NUCLEAR MAGNETIC RESONANCE SPECTRA}

ACQUISITION AND PROCESSING

Spectra were acquired in a $2.35 \mathrm{~T}, 40 \mathrm{~cm}$ bore, horizontal superconducting magnet (Biospec BNT100 spectrometer, Brüker, Germany). The $5 \mathrm{~cm}$ diameter surface coil could be tuned to both the ${ }^{1} \mathrm{H}(100.425 \mathrm{MHz})$ and ${ }^{31} \mathrm{P}(40.65 \mathrm{MHz})$ frequencies with the aid of tune/match circuits. The heart was maintained within its sterile container and positioned directly upon the coil. The field homogeneity was optimised by shimming on the proton signal; 128 free induction decays were accumulated over 2 minutes with a repetition time of $1.25 \mathrm{~s}$. The radiofrequency pulse length was $70 \mu \mathrm{s}$ and this corresponds to 
Nuclear magnetic resonance indices measured in 13 hearts at different times after excision ( $N$, normal hearts; valve, valve disease; $D C M$, dilated cardiomyopathy; MI, hearts post myocardial infarction).

\begin{tabular}{|c|c|c|c|c|c|}
\hline $\begin{array}{l}\text { Time after excision } \\
\text { (h) }\end{array}$ & $P_{i} / P C r$ & $P C r / A T P$ & $(P C r+P i) \mid A T P$ & $P D E \mid A T P$ & $p H$ \\
\hline $\begin{array}{c}N: \\
0.5 \\
9\end{array}$ & $\begin{array}{l}0 \cdot 18 \\
9 \cdot 04\end{array}$ & $\begin{array}{l}1.49 \\
0.19\end{array}$ & $\begin{array}{l}1.77 \\
1.98\end{array}$ & $\begin{array}{l}0.11 \\
0\end{array}$ & $\begin{array}{l}7.5 \\
6.6\end{array}$ \\
\hline $\begin{array}{l}\mathrm{N}: \\
0.5 \\
\text { Valve }\end{array}$ & 0.15 & 1.42 & 1.62 & 0.21 & $7 \cdot 3$ \\
\hline $\begin{array}{c}1 \\
3 \\
3\end{array}$ & $\begin{array}{l}0.61 \\
1.45\end{array}$ & $\begin{array}{l}0.72 \\
0.52\end{array}$ & $\begin{array}{l}1 \cdot 14 \\
1 \cdot 30\end{array}$ & $\begin{array}{l}0.17 \\
0.18\end{array}$ & $\begin{array}{l}7.3 \\
7 \cdot 3\end{array}$ \\
\hline $\begin{array}{l}\text { DCM: } \\
0 \cdot 5 \\
\text { DCM: }\end{array}$ & 0.32 & 0.78 & 0.96 & 0.35 & $7 \cdot 3$ \\
\hline $\begin{array}{l}0.5 \\
1 \\
2 \\
3 \\
9\end{array}$ & $\begin{array}{l}0.45 \\
0.92 \\
2.48 \\
7.28 \\
-\end{array}$ & $\begin{array}{l}0.84 \\
0.49 \\
0.29 \\
0.11 \\
0.0\end{array}$ & $\begin{array}{l}1.21 \\
0.94 \\
1.01 \\
0.92 \\
1.04\end{array}$ & $\begin{array}{l}0.12 \\
0.18 \\
0.25 \\
0.36 \\
0.0\end{array}$ & $\begin{array}{l}7.3 \\
7.1 \\
7.0 \\
6.8 \\
-\end{array}$ \\
\hline $\begin{array}{c}\text { DCM: } \\
0.5 \\
1\end{array}$ & $\begin{array}{l}1.50 \\
1.35\end{array}$ & $\begin{array}{l}0.65 \\
0.65\end{array}$ & $\begin{array}{l}1.61 \\
1.55\end{array}$ & $\begin{array}{l}0.060 \\
0.29\end{array}$ & $\begin{array}{l}- \\
7 \cdot 2 \\
7 \cdot 2\end{array}$ \\
\hline${ }_{\mathbf{D C}}^{\mathbf{6}}$ & 1.98 & 0.66 & 1.99 & 0.26 & $7 \cdot 1$ \\
\hline $\begin{array}{c}0.5 \\
1 \\
0 C M\end{array}$ & $\begin{array}{l}0.23 \\
0.54\end{array}$ & $\begin{array}{l}1.21 \\
0.69\end{array}$ & $\begin{array}{l}1.48 \\
1.05\end{array}$ & $\begin{array}{l}0.062 \\
0.016\end{array}$ & $\begin{array}{l}7.5 \\
7.3\end{array}$ \\
\hline $\begin{array}{l}\text { DCM: } \\
0.5 \\
1 \\
2 \\
3 \\
4 \\
4 .\end{array}$ & $\begin{array}{l}0.73 \\
0.59 \\
1.59 \\
2.3 \\
7.8\end{array}$ & $\begin{array}{l}0.56 \\
1.14 \\
0.44 \\
0.39 \\
0.14\end{array}$ & $\begin{array}{l}0.97 \\
1.82 \\
1.13 \\
1.27 \\
1.25\end{array}$ & $\begin{array}{l}0.035 \\
0.21 \\
0.49 \\
0.40 \\
0.32\end{array}$ & $\begin{array}{l}7.3 \\
7.2 \\
7.0 \\
6.9 \\
6.8\end{array}$ \\
\hline MI: & $1 \cdot 48$ & $0 \cdot 27$ & 0.68 & 0.082 & $7 \cdot 1$ \\
\hline MI: 0.5 & $\begin{array}{l}1.01 \\
3.08\end{array}$ & $\begin{array}{l}0.22 \\
0.12\end{array}$ & $\begin{array}{l}0.43 \\
0.87\end{array}$ & $\begin{array}{l}0.43 \\
0.040\end{array}$ & $\begin{array}{l}7.1 \\
7.0\end{array}$ \\
\hline $\begin{array}{l}\text { MI: } \\
0 \cdot 5 \\
1 \\
2 \\
3 \\
4\end{array}$ & $\begin{array}{l}0.33 \\
0.53 \\
0.94 \\
3.96 \\
7.38\end{array}$ & $\begin{array}{l}0.65 \\
0.65 \\
0.48 \\
0.25 \\
0.12\end{array}$ & $\begin{array}{l}0.87 \\
0.99 \\
0.94 \\
1.21 \\
1.00\end{array}$ & $\begin{array}{l}0 \\
0 \\
0.31 \\
0.29 \\
0.21\end{array}$ & $\begin{array}{l}7.4 \\
7.2 \\
7.1 \\
6.8 \\
6.6\end{array}$ \\
\hline $\begin{array}{c}\text { MI: } \\
0.5 \\
1 \\
2 \\
9\end{array}$ & $\begin{array}{l}1.28 \\
2.65 \\
4.63 \\
-\end{array}$ & $\begin{array}{l}0.39 \\
0.25 \\
0.22 \\
0.0\end{array}$ & $\begin{array}{l}0.90 \\
0.92 \\
1.27 \\
1.30\end{array}$ & $\begin{array}{l}0.22 \\
0.26 \\
0.27 \\
0.0\end{array}$ & $\begin{array}{l}7.1 \\
7.1 \\
7.0 \\
-\end{array}$ \\
\hline $\begin{array}{c}\text { MI: } \\
0.5 \\
1 \\
2\end{array}$ & $\begin{array}{l}0.41 \\
0.92 \\
1.11\end{array}$ & $\begin{array}{l}0.69 \\
0.57 \\
0.45\end{array}$ & $\begin{array}{l}0.97 \\
1.09 \\
0.96\end{array}$ & $\begin{array}{l}0.18 \\
0.14 \\
0\end{array}$ & $\begin{array}{l}7.6 \\
7.5 \\
7.2\end{array}$ \\
\hline
\end{tabular}

Figure 1 Spectra obtained from a donor heart studied 30 minutes after excision (bottom) and nine hours after excision (top). PME, phosphomonoester; Pi, inorganic phosphates; PCr, phosphocreatine. the maximum of signal for a repetition time of $1.25 \mathrm{~s}$. The total acquisition time was kept down to 5 minutes. The free induction decays were processed by conventional trapezoidal multiplication followed by a $15 \mathrm{~Hz}$ line broadening. The data were subsequently Fourier transformed and phase corrected to the zero and first order. The areas of inorganic phosphate ( $\mathrm{Pi})$, phosphocreatine (PCr), phosphodiesters (PDE), and $\beta$ ATP were measured by fitting lorentzian line shapes. The individual peak areas were corrected for $\mathrm{T} 1$ saturation effects by comparison with a reference spectrum acquired with a repetition

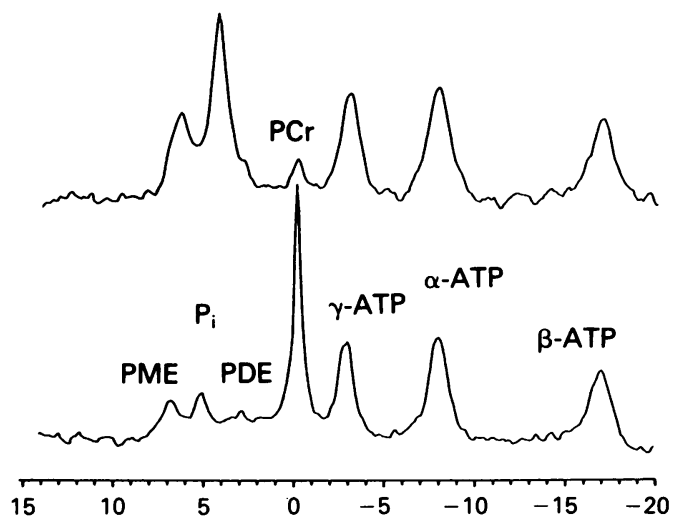

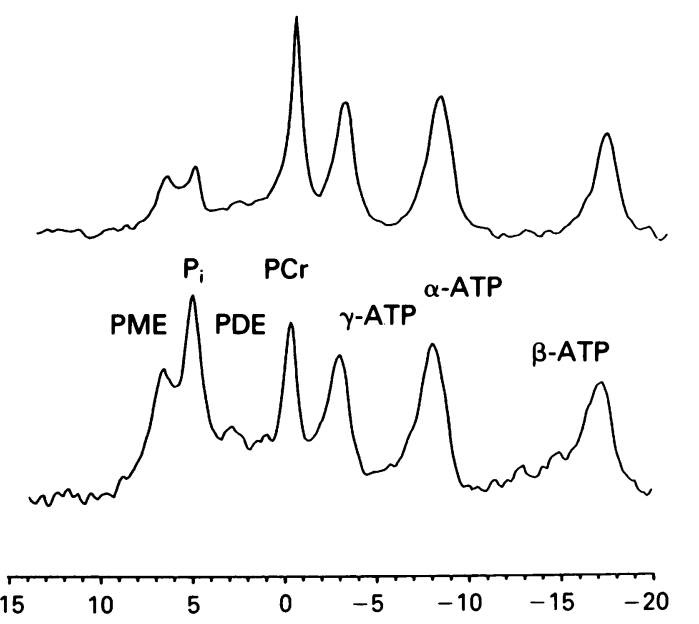

Figure 2 Spectra obtained 30 minutes after excision from two different recipient hearts with idiopathic cardiomyopathy. The ratio of the sum of inorganic phosphates and phosphocreatine to ATP was similar to that of donor hearts.

time of $20 \mathrm{~s}$. The chemical shift of phosphocreatine with respect to the inorganic phosphates was measured to give indirect information on $\mathrm{pH}$ by means of the following equation: $\mathrm{pH}=6.75+\log ((\mathrm{d}-3.27) /$ $5.69-\mathrm{d})$ ), where $\mathrm{d}=$ chemical shift in ppm. ${ }^{5}$

\section{STATISTICAL METHODS}

The results were expressed as mean (SD). Means were compared by Student's $t$ test.

\section{Results}

The results are expressed for each heart as the ratio of phosphocreatine to $\beta$ ATP (PCr/ATP), the ratio of inorganic phosphate to $\beta \mathrm{ATP}(\mathrm{Pi} /$ ATP), the ratio of phosphocreatine plus inorganic phosphate to $\beta \mathrm{ATP}$, and the $\mathrm{pH}$ (table)

Typical spectra are shown for three groups: normal hearts (fig 1), dilated cardiomyopathy (fig 2), and myocardial infarction (fig 3 ).

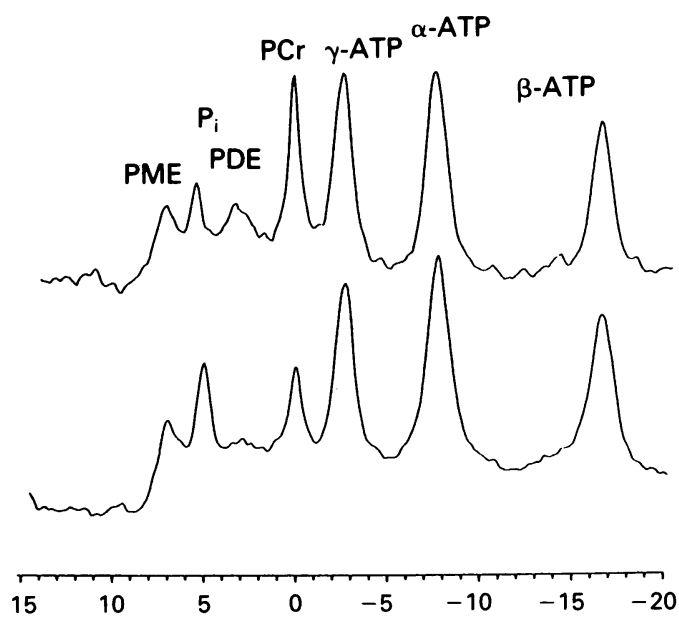

Figure 3 Spectra obtained 30 minutes after excision from two recipient hearts with coronary artery disease. The phosphocreatine concentration was low and this finding was not explained by a simultaneous increase in inorganic phosphates caused by breakdown of $\mathrm{PCr}$ because the sum of these two compounds remained low in comparison to ATP. 
Figure 4 (PCr $+P i)$ | ATP ratio calculated in $(N)$; dilated cardiomyopathy (DCM); (myocardial infarction (MI). three groups: donor hearts

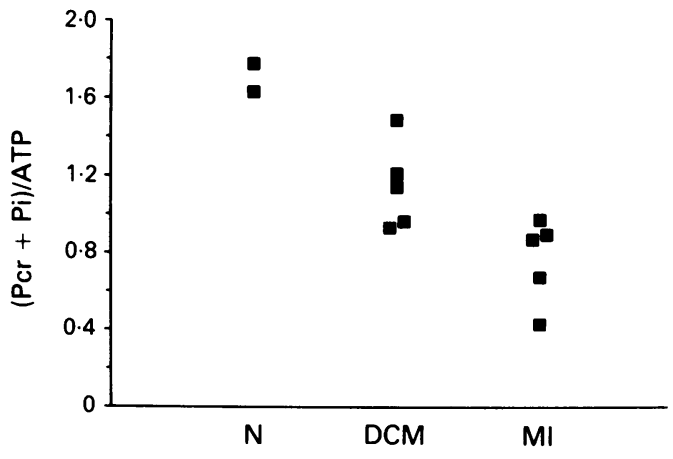

Pi/ATP increased and PCr/ATP decreased in the hours after the excision (table) whereas the ratio $(\mathrm{PCr}+\mathrm{Pi}) / \mathrm{ATP}$ remained stable. The PDE/ATP ratio varied without any noticeable trend. The $\mathrm{pH}$ became more and more acidic until the PCr disappeared and the $\mathrm{pH}$ could not be measured. Thirty minutes after the excision $(\mathrm{PCr}+\mathrm{Pi}) / \mathrm{ATP}$ was 1.69 $(0.11)$ in normal hearts, $1.25(0.29)$ in dilated cardiomyopathy (NS), and $0.77(0.22)$ in myocardial infarct $(p<0.01 v$ normal hearts and $\mathrm{p}<0.05 v$ dilated cardiomyopathy)(fig 4). No significant difference was found for thePDE/ ATP ratio (fig 5): $0 \cdot 16(0.07)$ in normal hearts, $0 \cdot 125(0 \cdot 13)$ in dilated cardiomyopathy and $0 \cdot 18(0 \cdot 16)$ in myocardial infarction. There was no difference in $\mathrm{pH}$ between the three groups (fig 6) $(7.4(0.1)$ in normal hearts, $7.3(0.1)$ in dilated cardiomyopathy, and $7 \cdot 3(0.2)$ in myocardial infarction).

\section{Discussion}

Our study confirms that examination of whole excised human hearts by magnetic resonance spectroscopy is feasible with a wide bore horizontal magnet. Inorganic phosphates and phosphocreatine cannot be analysed separately in our study because during the cardioplegia and the first minutes of conservation breakdown of phosphocreatine is highly variable. The sum of phosphocreatine and inorganic phosphates gives an indication of the maximum amount of phosphocreatine in the heart at excision. We expressed the result as a ratio to $\beta$ ATP because ATP values remain constant when phosphocreatine is still detectable. The lack of a significant change in the ratio $(\mathrm{PCr}+\mathrm{Pi}) / \beta$ ATP during the initial hours after excision, despite the breakdown of

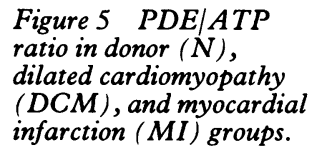

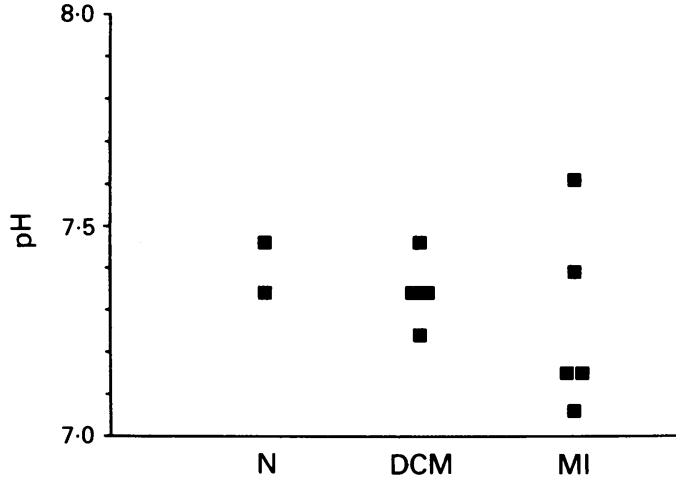

Figure 6 pH calculated in donor $(N)$, dilated cardiomyopathy (DCM), and myocardial infarction (MI) groups.

phosphocreatine, is indirect evidence that this assumption is correct.

In the two normal hearts the $(\mathrm{PCr}+\mathrm{Pi}) / \beta$ ATP ratio was 1.69 -that is, in the same range as the ratio PCr/ATP measured in open chest pig in vivo. ${ }^{6}$ In the perfused guinea-pig heart this ratio was about $1 \cdot 8 .^{1}$ It seems likely that the normal PCr/ATP ratio in human hearts measured by nuclear magnetic resonance would be similar to the ratio in these two species. In one normal heart phosphocreatine was still detectable nine hours after excision. This suggested that the heart might still have been viable. This accords with previous findings by Van Echteld et $\mathrm{al}^{3}$ and suggests that the rate of decrease of phosphocreatine in excised human heart is much slower than in hearts from small animals.

With competent technical support and adequate instrumentation a heart graft can be quickly examined. But nuclear magnetic resonance study of heart grafts cannot be recommended for two reasons: there are no reliable experimental or clinical data to show that magnetic resonance spectroscopy could predict the haemodynamic viability of the graft. Because the graft can be conserved only for a limited time the surgical procedure must be underway in the recipient when the graft arrives and the study in the magnet could delay the transplantation itself. Nevertheless, the development of techniques that allow the heart to be conserved for more than six hours could make nuclear magnetic resonance spectroscopy a useful adjunct for deciding whether the heart is viable for transplantation.

Because we studied recipient hearts under the same conditions as normal hearts, the differences we saw cannot be explained by differences in the temperature, time after excision, or nuclear magnetic resonance measurement techniques. In the failing heart, the $(\mathbf{P C r}+\mathbf{P i}) / \mathbf{A T P}$ ratio is significantly lower in infarcted hearts, but can be nearly normal in dilated cardiomyopathy even at the terminal stage of heart failure when a heart transplant is required. Differences between hearts with myocardial infarction and dilated cardiomyopathy cannot be explained by different ejection fractions or pulmonary artery pressures. In isolated perfused rat hearts the ratio PCr/ATP reflected the imbalance between 
metabolic demand and energy supply which led to a reduction of the percentage of creatine that is phosphorylated. ${ }^{1}$ It could be argued that a partial volume effect from the scar and the surrounding jeopardised myocardium could modify the measurements in a heterogeneous myocardium but it is unlikely that this effect could modify results expressed as a ratio of phosphocreatine to ATP. Another hypothesis is that the concentration of the total creatine falls. Such a fall was seen in human myocardium with hypertrophy caused by aortic stenosis and in the myocardium of patients with coronary artery disease. ${ }^{7}$ The reduced PCr/ATP ratio in ischaemic heart diseases could reflect a metabolic adaptation either to the hypertrophy of the non-infarcted area or to the ischaemia induced by the coronary artery disease itself. Further studies are needed to clarify these issues.

Myocardial $\mathrm{pH}$ calculated by the classic formula was rather alkaline. This is due to hypothermia. ${ }^{8}$ Use of another $\mathrm{pH}$ titration curve $(\mathrm{pH}=6 \cdot 88+\log (\mathrm{d}-3.35) / 5 \cdot 6-\mathrm{d}))$ established at $4^{\circ} \mathrm{C}^{9}$ would have led to even more alkaline $\mathrm{pH}$ values. Any attempt to correct for these effects of temperature would induce a parallel modification of the calculated $\mathrm{pH}$ in all the studied hearts and no intergroup significant differences would appear, suggesting that the $\mathrm{pH}$ is not modified even in severe heart diseases.

We found no difference in the concentration of phosphodiesters between the different groups we studied. Phosphodiesters have an NMR frequency between inorganic phosphates and phosphocreatine. They are regarded as being a consequence of muscle modifications both in myocardium ${ }^{10}$ and in skeletal muscle. ${ }^{11}$ The fact that the hearts were studied with a minimum quantity of blood after the infusion of the cardioplegic medium suggests that in some cases the reported PDE peak during in vivo studies could have been related to a partial volume effect of blood. Our data suggest that phosphodiesters do not aid the identification of different types of myocardial disease.
Our data provide information on the phosphorus spectroscopy findings in normal and diseased hearts and should contribute to a better understanding of the spectra obtained in vivo. Further work is needed to explain the observed decrease of the $\mathrm{PCr} / \mathrm{ATP}$ ratio in ischaemic hearts.

We thank Professor G K Radda, Dr B Rajagopalan, and Dr AM Seymour for helpful discussions.

1 Brooks WM, Haseler LJ, Clarke K, Willis RJ. Relation between the phosphocreatine to ATP ratio determined by ${ }^{31} \mathrm{P}$ nuclear magnetic resonance spectroscopy and left ventricular function in underperfused guinea-pig heart J Mol Cell Cardiol 1986;18:149-55.

2 Hardy CJ, Weiss RG, Bottomley PA, Gerstenblith G Chackov $P$. Localized phosphorus 31 nuclear magnetic resonance spectroscopy in humans with dilated cardiomyopathy. Society of Magnetic Resonance in Medicine. 8th annual meeting. August 1989. Amsterdam, p 509

3 Van Echteld CJA, Kirkels JH, Jambroes G, Kodde JH, Lahpor JR, Ruigrok TJC. Human donor heart preservation assessed by ${ }^{31} \mathrm{P}$ nuclear magnetic resonance spectroscopy. Society of Magnetic Resonance in Medicine. 8th annual meeting. August 1989. Amsterdam, p 512

4 Rajagopalan B, Blackledge MJ, McKenna WJ, Bolas N, Radda GK. Measurement of phosphocreatine to ATP ratio in normal and diseased human heart by ${ }^{31} \mathrm{P}$ magnetic resonance spectroscopy using the rotating frame-depth resonance spectroscopy using the rotating frame-depth selection technique. Ann NY Acad Sci 1987;508:321-32.

5 Taylor DJ, Bore RJ, Styles P, Gadian DG, Radda GK Bioenergetics of intact human muscle: a $31-\mathrm{P}$ nuclear magnetic resonance study. Mol Biol Med 1983;1:77-94.

6 Rajagopalan B, Bristow JD, Radda GK. Measurement of transmural distribution of phosphorus metabolites in the pig heart by ${ }^{31} \mathrm{P}$ magnetic resonance spectroscopy. Cardiovasc Res 1989;23:1015-26.

7 Ingwall JS, Kramer MF, Fifer MA, Lorell BH, Shemin R, Grossman W, Allen PD. The creatine kinase system in normal and diseased human myocardium. $N$ Engl J Med 1985;313:1050-54.

8 White FN. A comparative physiological approach to hypothermia. $J$ Thorac Cardiovasc Surg 1988;82:821-31.

9 English TA, Foreman J, Gadian DG, Pegg DE, Wheeldon D, Williams SR. Three solutions for preservation of the D, Williams SR. Three solutions for preservation of the nuclear magnetic resonance spectroscopy. $J$ Thorac nuclear magnetic resonance
Cardiovasc Surg 1988;96:54-61.

10 Shaefer S, Schwartz GG, Gober JR, Meyerhoff DJ, Weiner $\mathrm{MW}$, Massie B. ${ }^{31} \mathrm{P}$ spectroscopic imaging of global myocardial disease: elevation of phosphodiesters in patients with left ventricular dilation [abstract]. Circulation 1989;80:588.

11 Burt CT, Pluskal MG, Streter FA. Generation of phosphodiesters during fast to slow muscle transformation. A ${ }^{31} \mathrm{P}$ Nuclear magnetic resonance study. Biochem Biophys Acta 1982;721:492-4. 